\title{
THE EFFECTS OF INTERSPECIFIC INTERACTIONS BETWEEN BLOOM FORMING CYANOBACTERIA AND SCENEDESMUS QUADRICAUDA (CHLOROPHYTA) ON THEIR PHOTOPHYSIOLOGY
}

\author{
Attila W. Kovács, * Viktor R. Tóth and Károly PÁlffy \\ Department of Hydrobotany, MTA Centre for Ecological Research, Balaton Limnological Institute, \\ Klebelsberg Kuno u. 3, H-8237 Tihany, Hungary
}

(Received: December 1, 2017; accepted: December 30, 2017)

\begin{abstract}
Eutrophication and enhanced external nutrient loading of lakes and seas are most clearly reflected by increased cyanobacterial blooms, which are often toxic. Freshwater cyanobacteria produce a number of bioactive secondary metabolites, some of which have allelopathic properties, significantly influencing the biological processes of other algae, thereby affecting species composition and succession of the phytoplankton. The goal of this work was to investigate the influence of bloom-forming cyanobacterial exudates on the photophysiology of the green alga Scenedesmus quadricauda by chlorophyll fluorescence analysis. We were able to prove the effect of algal cell-free filtrates on the performance of $S$. quadricauda and demonstrate for the first time that the freshwater picocyanobacterium Cyanobium gracile has strong negative impact on the coexisting green alga. Neither the cyanotoxin (MYC, CYN and ATX) producing, nor the non-toxic strains showed any systematic effect on the production of $S$. quadricauda. Various strains of the cyanobacterium Cylindrospermopsis raciborskii inhibited the performance of the green alga independently of their origin. Our results urge further studies for a better understanding of the factors affecting the release of allelopathic compounds and the mechanisms of their effects on target organisms.
\end{abstract}

Keyword: Allelopathy - cell-free extract - chlorophyll fluorescence - rapid light curves - Cylindrospermopsis raciborskii - picocyanobacteria

\section{INTRODUCTION}

Eutrophication, i.e. the enrichment of water bodies with plant nutrients, sometimes results in extremely high levels of phytoplankton biomass called algal blooms, and also alters the food web within the aquatic ecosystem. Under these conditions, various abiotic and biotic factors other than nutrients will be the source of competition, which could significantly influence phytoplankton composition [29]. Phytoplankton blooms drastically decrease the availability of light, making it a very strong selective force, while on the biotic side, chemically mediated interactions between the algal components of the aquatic ecosystem could also significantly influence phytoplankton succession $[14,16]$.

\footnotetext{
*Corresponding author; e-mail address: kovacswa@gmail.com
} 
Eutrophication of lakes and seas are usually accompanied by an increase in the frequency and amplitude of cyanobacterial blooms, which are often toxic $[24,26]$. Furthermore, future climate change scenarios predict rising temperatures [3], which can act as a catalyst for the global expansion of harmful cyanobacterial blooms $[12,26]$. As the frequency of cyanobacterial blooms is increasing worldwide, their allelopathic influence on other aquatic organisms is attracting growing attention.

Cyanobacteria produce several bioactive secondary metabolites with diverse chemical structure, which may achieve high concentrations in the aquatic medium when cyanobacterial blooms occur [43]. Some of these compounds have allelopathic properties, influencing the biological processes of other planktonic algae or aquatic plants [16]. Since Keating $[14,15]$ pointed out that allelopathy could be the main factor triggering cyanobacterial blooms, and hence influence phytoplankton succession, many studies have been dedicated to this hypothesis, as reviewed by Figueredo [7] and Legrand et al. [18].

Nevertheless, the role of allelopathy in cyanobacterial ecology is still not well understood. Most of the identified allelochemicals have been characterized as algicides that directly inhibit photosynthetic electron transport in cyanobacteria and eukaryotic algae by binding to specific sites in the vicinity of photosystem II [38, 43]. One of the methods used for studying the photophysiology of autotrophs is chlorophyll fluorescence analysis that allows non-invasive, near-instantaneous measurement of the key aspects of photosynthetic light capture and electron transport [20].

As in many freshwaters, the eutrophication of Lake Balaton (Hungary) has been associated with an increasing dominance of cyanobacteria [25, 45]. Generally, after the collapse of the spring diatom bloom, green algae (Scenedesmus genus, Oocystis, Planktonema) become typical in the water, after which cyanobacteria outcompete the others and dominates the algal community in summer [29,39]. Thus, the goal of this work was to investigate the influence of bloom forming cyanobacteria on the photophysiology of Scenedesmus quadricauda, a ubiquitous microalga also found in Lake Balaton, by chlorophyll fluorescence analysis. We hypothesised that while S. quadricauda photophysiology would be affected by toxin producing strains, non-toxic phytoplankton would have no significant effect.

\section{MATERIALS AND METHODS}

\section{Organisms and growth conditions}

To test the allelopathic effect of different strains of cyanobacteria on the target species, Scenedesmus quadricauda, was subjected to cell-free filtrates (CFF) obtained from $S$. quadricauda itself, and from toxic and non-toxic strains of cyanobacteria typical for temperate climate (Table 1). The ACT strains were isolated from Lake Balaton (Hungary). The SAG strains and PCC strain were obtained from the Culture Collection of Algae at Göttingen University (Germany), and from the Pasteur Culture 


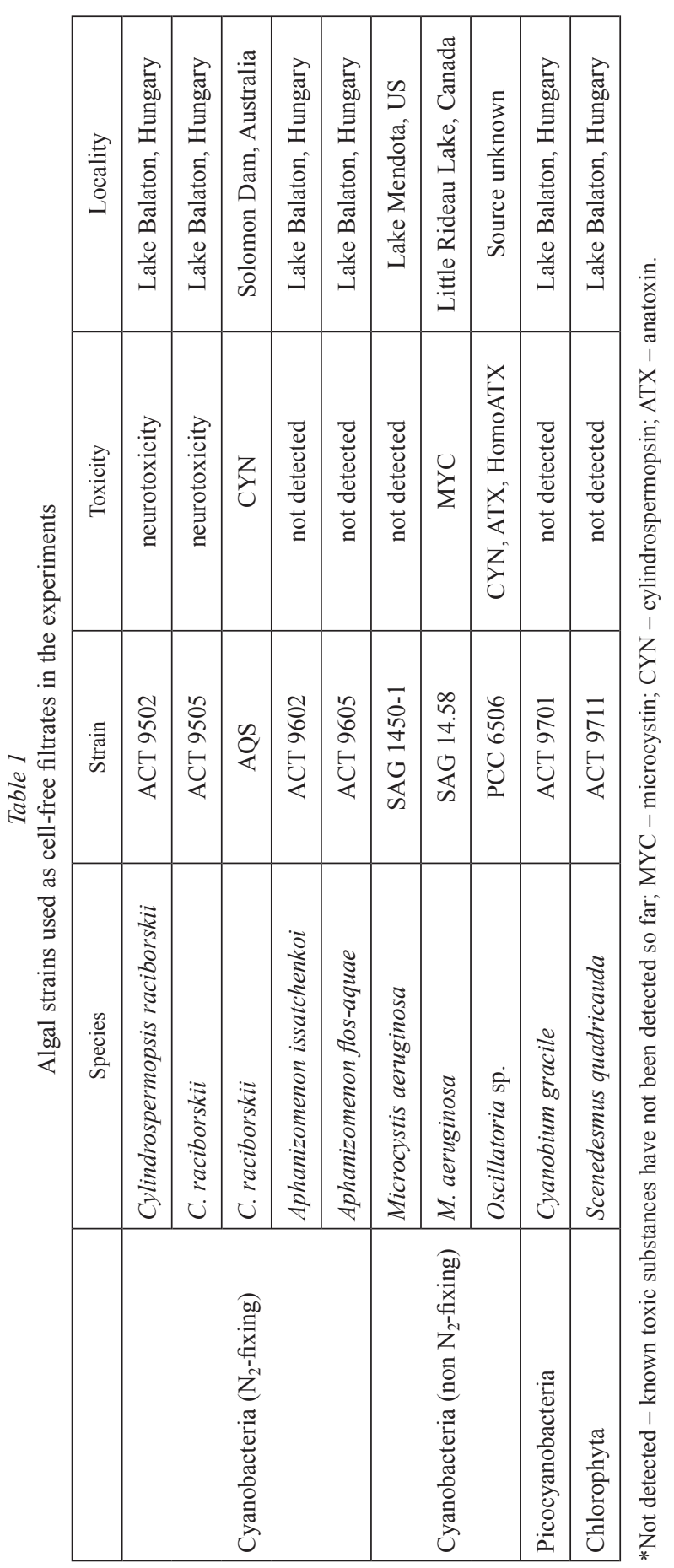

Acta Biologica Hungarica 69, 2018 
Collection of Cyanobacteria (France), respectively. The AQS strain was provided by Martin L. Saker (University of Porto, Portugal).

The organisms were grown as batch cultures in $500 \mathrm{ml}$ Erlenmeyer flasks filled with $200 \mathrm{ml} \mathrm{BG} 11$ medium [30] at $22^{\circ} \mathrm{C}$. The medium of $\mathrm{N}_{2}$-fixing species was $\mathrm{N}\left(\mathrm{NaNO}_{3}\right)$ free. Illumination was provided by fluorescence tubes $(36 \mathrm{~W}, \mathrm{~F} 33$, Cool-white, Tungsram, Hungary) under 14/10-h light/dark cycles and a photosynthetic photon flux density of $80 \mu \mathrm{mol}$ photons $\mathrm{m}^{-2} \mathrm{~s}^{-1}$. Cultures were stirred three times a day.

CFFs are filtrates containing excretions of the organisms. CFFs were prepared from intact algal cultures (Table 1) in their early stationary phase of growth by sequential filtering through glass-fiber filters $(\mathrm{GF} / \mathrm{C}$, Whatman, pore size $1.2 \mu \mathrm{m}$, ) and cellulose mixed ester filters (Porafil MV, Macherey-Nagel, pore size $0.2 \mu \mathrm{m}$ ). CFFs were added to culture flask containing $S$. quadricauda (in the exponential phase of growth diluted with fresh medium) in a ratio of $0.25: 1$. Final chlorophyll- $a$ concentration was $185 \mu \mathrm{g} \mathrm{L}^{-1}$ (determined by methanol extraction [9]) in the test tubes. Controls were prepared by adding an equal volume of normal and $\mathrm{NaNO}_{3}$ free BG11 medium. S. quadricauda cultures were subjected to CFFs for six days in triplicates. Photophysiological effect of CFFs was measured in early phase ( $12 \mathrm{~h}$ after incubation - named day 1 in the text) and at the end of the experiments (after six days - named day 6 in the text).

\section{Photochemical measurements}

Photochemical parameters and light response curves of $S$. quadricauda cultures were determined in a stirred suspension cuvette after a dark adaptation period of $20 \mathrm{~min}$ using PAM-2500 (Heinz Walz GmbH, Germany). The fluorescence of the dark adapted cultures (minimum fluorescence yield $-\mathrm{F}_{0}$ ) was the first parameter to be measured followed by the maximum fluorescence yield $\left(\mathrm{F}_{\mathrm{m}}\right)$ after a pulse of a saturating light $\left(630 \mathrm{~nm}\right.$, intensity $\left.3000 \mu \mathrm{mol} \mathrm{m}^{-2} \mathrm{~s}^{-1}\right)$. Later, the cultures were exposed to 11 actinic lights (duration $15 \mathrm{~s}, 630 \mathrm{~nm}$, intensity between 5 and $787 \mu \mathrm{mol} \mathrm{m}^{-2} \mathrm{~s}^{-1}$ ) with the electron transport rate measured after each illumination step with a new pulse of saturating light. The potential quantum yield of photosystem II (PSII) $\left(\mathrm{F}_{\mathrm{v}} / \mathrm{F}_{\mathrm{m}}\right)$, the relative electron transport rate (rETR), the coefficient of photochemical fluorescence quenching (qP) and the coefficient of nonphotochemical fluorescence quenching (qN) were calculated according to Bilger [2], Schreiber [32] and Schreiber et al. [33].

\section{Data analysis}

The light response data were fitted with exponential saturating curve [5]. Maximum electron transport rate $\left(\mathrm{ETR}_{\max }\right)$, theoretical saturation light intensity $\left(\mathrm{I}_{\mathrm{k}}\right)$, and the maximum quantum yield for whole chain electron transport $(\alpha)$ were retrieved using the native software of the PAM-2500. Data visualisation was performed using OriginPro 2017 (OriginLab Cooperation, USA). Statistics ( $t$-test and 2-way ANOVA) were performed in R v.3.4.0. 


\section{RESULTS}

\section{The effect of algal CFF on the fluorescence properties of S. quadricauda}

The acute (12 h) effect of CFFs on $\mathrm{F}_{\mathrm{v}} / \mathrm{F}_{\mathrm{m}}$ of $S$. quadricauda was not uniform, since some of the CFFs increased (PCC6506), some decreased (ACT9602, ACT9701) it, though the majority of the CFFs had no effect at all (Fig. 1). In general, the toxic algal

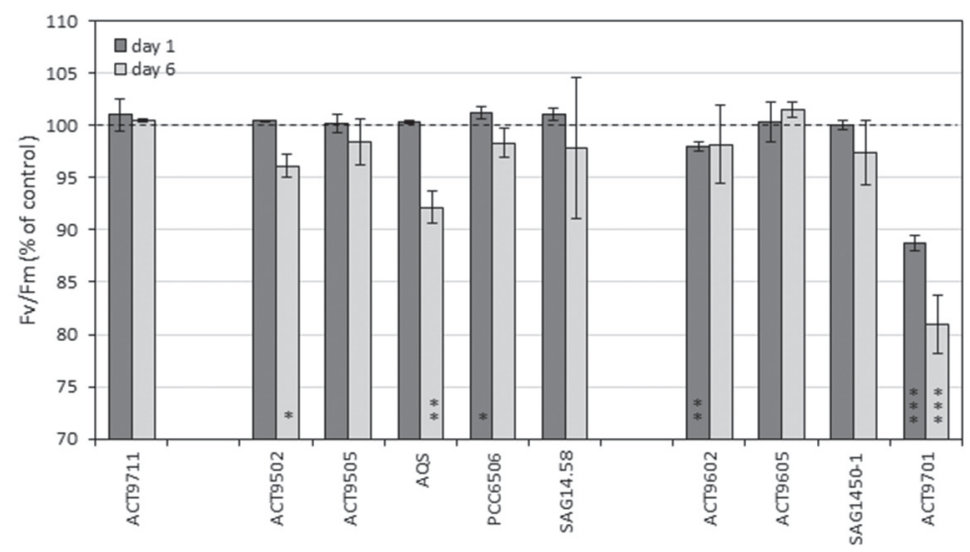

Fig. 1. Effect of cell free filtrates on Scenedesmus quadricada's potential quantum yield of photosystem II $\left(\mathrm{F}_{\mathrm{v}} / \mathrm{F}_{\mathrm{m}}\right)$. Left group of bars are $S$. quadricauda, central group of bars are potentially toxic cyanobacteria and right group of bars are non-toxic cyanobacteria. $\mathrm{F}_{\mathrm{v}} / \mathrm{F}_{\mathrm{m}}$ was calculated as $\%$ of that of control (average $\pm \mathrm{SD})$. $t$-test results between the control and the treatment are shown as: $* \mathrm{P}<0.05, * * \mathrm{P}<0.01$, $* * * \mathrm{P}<0.001$

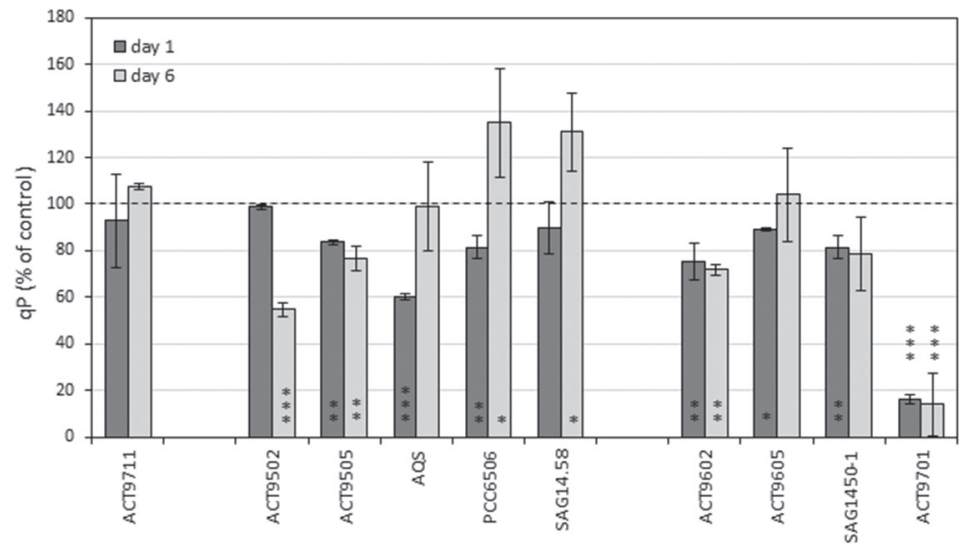

Fig. 2. Effect of cell free filtrates on Scenedesmus quadricada's photochemical fluorescence quenching (qP). Left group of bars are $S$. quadricauda, central group of bars are potentially toxic cyanobacteria and right group of bars are non-toxic cyanobacteria. qP was calculated as $\%$ of that of control (average $\pm \mathrm{SD}$ ). $t$-test results between the control and the treatment are shown as: $* \mathrm{P}<0.05, * * \mathrm{P}<0.01,{ }^{*} * * \mathrm{P}<0.001$ 
strains increased $(0.68 \pm 0.00)$, while the non-toxic strains decreased the $\mathrm{F}_{\mathrm{v}} / \mathrm{F}_{\mathrm{m}}$ of $S$. quadricauda to $0.65 \pm 0.00$, thought the differences were not significant. The prolonged (6 days) exposure to CFFs decreased the $\mathrm{F}_{\mathrm{v}} / \mathrm{F}_{\mathrm{m}}$ of $S$. quadricauda from $0.66 \pm 0.01$ to $0.64 \pm 0.01(t$-test, $\mathrm{t}=1.878$ and $\mathrm{P}=0.042)$ and $0.63 \pm 0.01(\mathrm{t}=1.025$ and $\mathrm{P}=0.162$ ) for toxic and non-toxic algae, respectively (Fig. 1). The strains separately had mostly no significant effect on $\mathrm{F}_{\mathrm{v}} / \mathrm{F}_{\mathrm{m}}$, though CFF of the picocyanobacterium (ACT9701) decreased the $\mathrm{F}_{\mathrm{v}} / \mathrm{F}_{\mathrm{m}}$ of $S$. quadricauda to $0.53 \pm 0.02(\mathrm{t}=13.07$ and $\mathrm{P}<0.001$ ) (Fig. 1). In addition, the CFFs of two C. raciborskii strains (ACT 9502 and AQS) also had a significant negative effect $(\mathrm{P}=0.036$ and $\mathrm{P}=0.003$, respectively).

More prominent effects were observed with regard to the coefficient of photochemical fluorescence quenching (qP) in S. quadricauda as 7 acute and 4 prolonged exposures had a negative, while 2 prolonged exposures had a positive effect (Fig. 2). In general, the toxic strains had an acute effect, causing a decrease in $\mathrm{qP}$ from 0.22 to 0.18 after the first $12 \mathrm{~h}(t$-test, $\mathrm{P}=0.023)$, although after 6 days of exposure to CFF the changes diminished ( $t$-test, $\mathrm{P}=0.47$ ). On the other hand, the acute effect of non-toxic strains was more prominent (from 0.22 to $0.15, \mathrm{P}=0.008$ ), and was still observed after 6 days $(\mathrm{P}=0.038)$ (Fig. 2). The acute exposure had a negative effect in the case of strains ACT9505 (-16.3\%), AQS (-40\%), PCC6506 (-18.4\%), ACT9602 (-24.5\%), ACT9605 (-10.1\%), SAG1450-1 (-9.98\%) and ACT9701 (-84\%) (Fig. 2). On the other hand, after the prolonged exposure of 6 days, $\mathrm{qP}$ decreased when the green alga was treated with the CFF of ACT9502 (-45.3\%), ACT9505 (-23.4\%) ACT9602 $(-28.22 \%)$ and ACT9701 (-86\%), while those of strains PCC6506 $(+134.8 \%)$ and SAG14.58 (+130.9\%) elicited an increase (Fig. 2). The CFF of strain ACT9701 had the most prominent effect after both the acute and the prolonged exposure.

The non-photochemical fluorescence quenching (qN) of $S$. quadricauda significantly decreased after a 12 hour-long exposure in all treatments, except the $C$. raciborskii strain ACT 9502 (Fig. 3). In general, the toxic strains decreased qN from 0.83

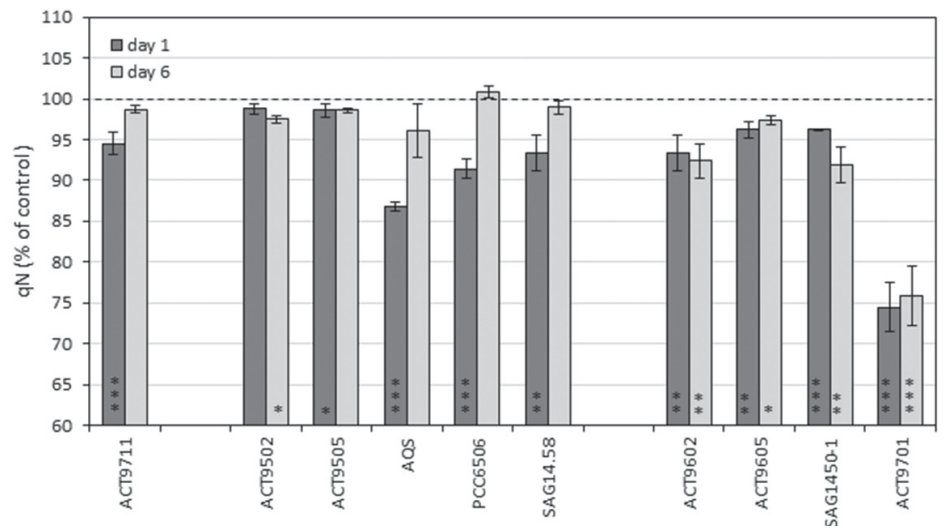

Fig. 3. Effect of cell free filtrates on Scenedesmus quadricada's non-photochemical fluorescence quenching (qN). Left group of bars are S. quadricauda, central group of bars are potentially toxic cyanobacteria and right group of bars are non-toxic cyanobacteria. $\mathrm{qN}$ was calculated as $\%$ of that of control (average $\pm \mathrm{SD}$ ). $t$-test results between the control and the treatment are shown as: $* \mathrm{P}<0.05, * * \mathrm{P}<0.01$, $* * * \mathrm{P}<0.001$ 
to $0.78(\mathrm{P}=0.003)$, though this effect diminished by day $6(\mathrm{P}=0.092)$. On the other hand, $\mathrm{CFF}$ of the non-toxic strains decreased qN to $0.75(\mathrm{P}=0.006)$, and maintained the effect $(\mathrm{P}=0.011)$ even on day 6 (Fig. 3). The qN of $S$. quadricauda also decreased to acute exposure of its own CFFs (ACT9711, $-6 \%$ ), although this effect diminished with time (Fig. 3). The most characteristic change was observed in the picocyanobacterium (ACT 9701) CFF treatment (26 and 24\% decline in the acute and prolonged exposure, respectively). Other strains decreased qN by $3-13 \%$ in acute exposure and by $2-8 \%$ in prolonged exposure.

\section{The effect of algal CFF on the fuorescence light curves}

The rapid light response curves of control Scenedesmus cultures had a theoretical saturation light intensity $\left(\mathrm{I}_{\mathrm{k}}\right)$ of $137 \pm 5 \mu \mathrm{mol} \mathrm{m}^{-2} \mathrm{~s}^{-1}$, maximal electron transport rate $\left(\mathrm{ETR}_{\max }\right)$ of $24.2 \pm 0.5$ and a maximum quantum yield for whole chain electron transport $(\alpha)$ of $0.18 \pm 0.00$ (Fig. 4). No photoinhibition was observed in the control treatment within the light intensity range of the study. The light curves of CFF treated

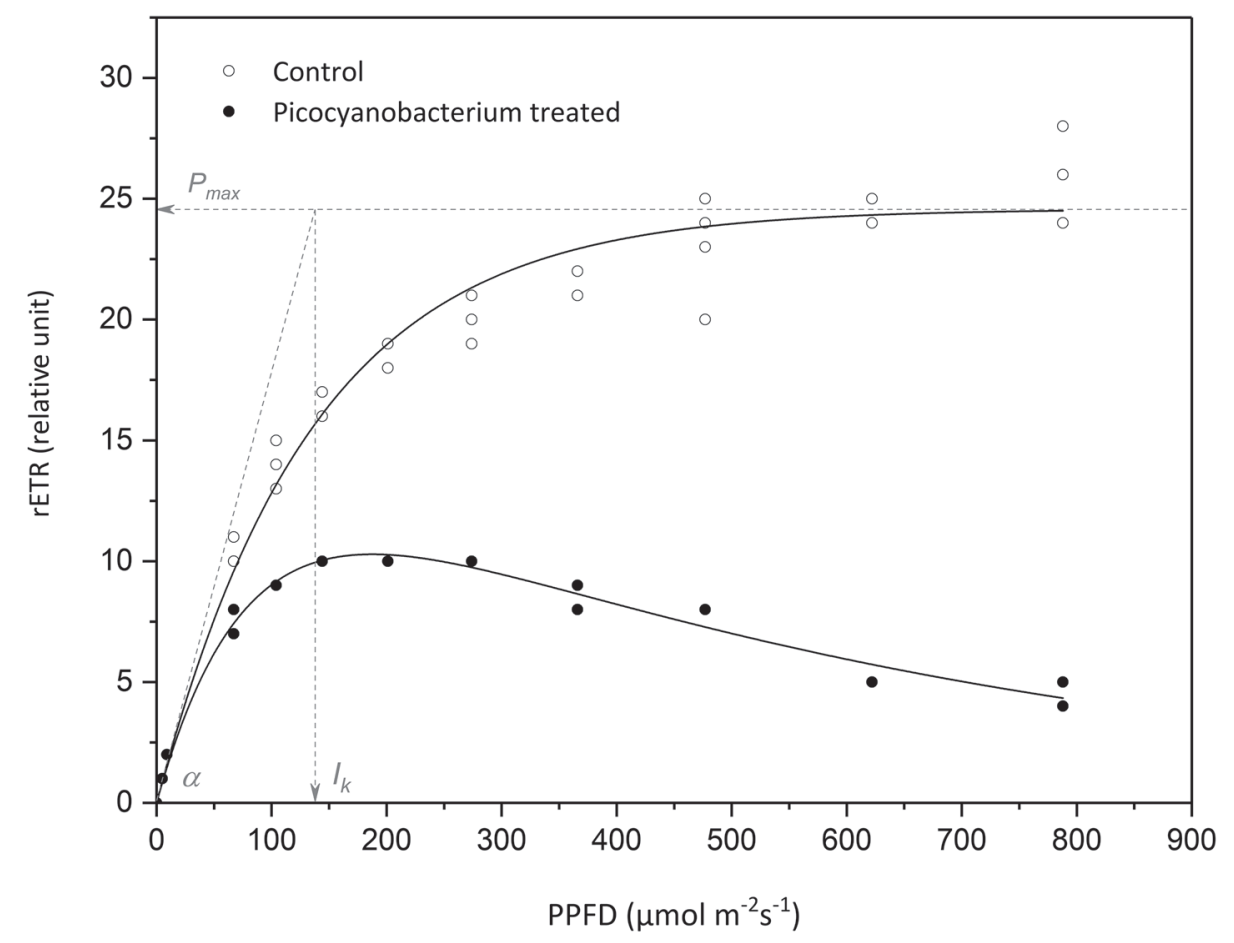

Fig. 4. Rapid light response curves and cardinal parameters for PS II electron transport in Scenedesmus quadricauda. Open circles show control, black symbols show cell free filtrate (picocyanobacteria strain ACT 9701) treated algae 
cultures showed a slightly different saturation pattern: lower $\mathrm{ETR}_{\max }$ and $\mathrm{I}_{\mathrm{k}}$, and higher $\alpha$, sometimes with prominent photoinhibition (Fig. 4).

In general, neither the toxic, nor the non-toxic strains had any systematic effect on the $\mathrm{ETR}_{\max }$ of $S$. quadricauda cultures, there was significant variance within the two groups (Fig. 5). The acute exposure to strains ACT9505, AQS, ACT9602 and ACT9701 decreased the ETR max $_{\text {ax }}$ of the treated culture by $10,12,10$ and $58 \%$, respectively (Fig. 5). Prolonged exposure increased ETR max $_{\text {in }}$ the case of ACT9711 (selfexposure, 15\%) and PCC6506 (30\%), while strain ACT9502, ACT9505 and ACT9701 had a decreasing effect (42, 21 and 56\%, respectively) (Fig. 5).

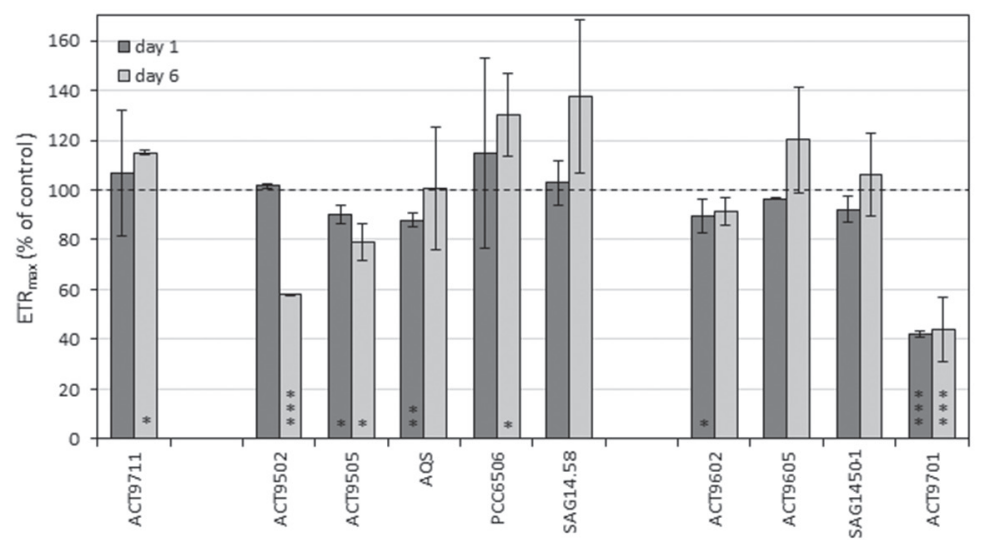

Fig. 5. Effect of cell free filtrates on Scenedesmus quadricada's maximal electron transport rate of photosystem II (ETR $\mathrm{Emax}_{\text {ma }}$. Left group of bars are $S$. quadricauda, central group of bars are potentially toxic cyanobacteria and right group of bars are non-toxic cyanobacteria. ETR $\mathrm{max}_{\max }$ was calculated as \% of that of control (average $\pm \mathrm{SD}$ ). $t$-test results between the control and the treatment are shown as: $* \mathrm{P}<0.05$, $* * \mathrm{P}<0.01, * * * \mathrm{P}<0.001$

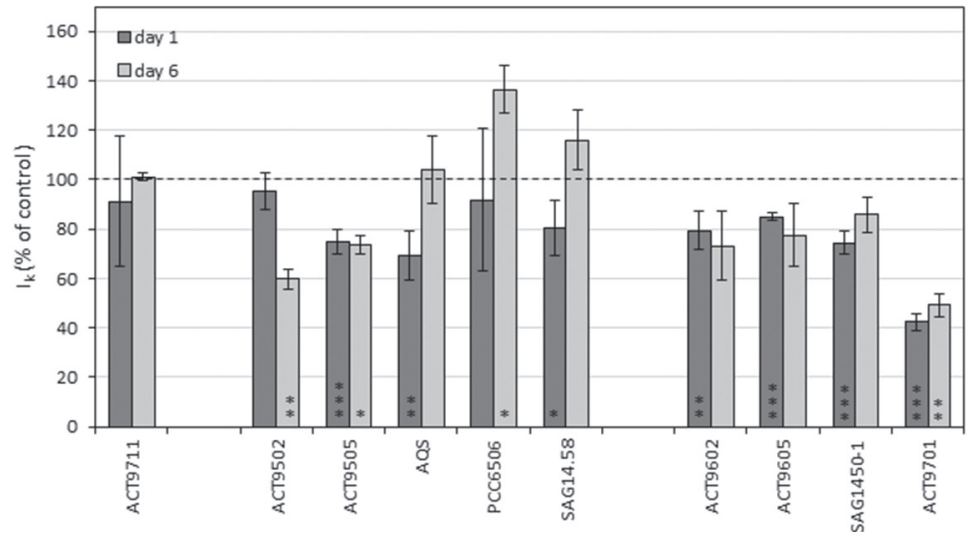

Fig. 6. Effect of cell free filtrates on Scenedesmus quadricauda's theoretical saturation light intensity $\left(\mathrm{I}_{\mathrm{k}}\right)$ of photosystem II. Left group of bars are $S$. quadricauda, central group of bars are potentially toxic cyanobacteria and right group of bars are non-toxic cyanobacteia. $I_{k}$ was calculated as $\%$ of that of control (average $\pm \mathrm{SD}$ ). $t$-test results between the control and the treatment are shown as: ${ }^{*} \mathrm{P}<0.05, * * \mathrm{P}<0.01$, $* * * \mathrm{P}<0.001$ 
Acute exposure to CFFs of toxic and non-toxic algal strains significantly decreased the $\mathrm{I}_{\mathrm{k}}$ of $S$. quadricauda from $137 \mu \mathrm{mol} \mathrm{m}^{-2} \mathrm{~s}^{-1}$ to $113(t$-test, $\mathrm{P}=0.003)$ and 102 $\mu \mathrm{mol} \mathrm{m}{ }^{-2} \mathrm{~s}^{-1}(t$-test, $\mathrm{P}=0.002)$, respectively (Fig. 6). However, this negative effect in the toxic strains diminished by day 6 , while in the non-toxic strains it was still obvious ( $t$-test, $\mathrm{P}=0.025$ ) (Fig. 6). The acute exposure to CFFs of strains ACT9505, AQS, SAG14.58, ACT9602, ACT9605, SAG1405-1 and ACT9701 reduced the $I_{k}$ of $S$. quadricauda cultures. Prolonged exposure to the CFF of PCC6506 resulted in an increase of $\mathrm{I}_{\mathrm{k}}(+36 \%)$, while those of strains ACT9502, АCT9505 and ACT9701 caused a decrease. In both the acute and prolonged exposure, strain ACT9701 had the most noticeable effect on the $\mathrm{I}_{\mathrm{k}}$ of the $S$. quadricauda culture (-57 and $-50 \%$, respectively).

The maximum quantum yield for whole chain electron transport $(\alpha)$ of PSII significantly increased from 0.18 to 0.22 and 0.20 during acute exposure to the toxic and

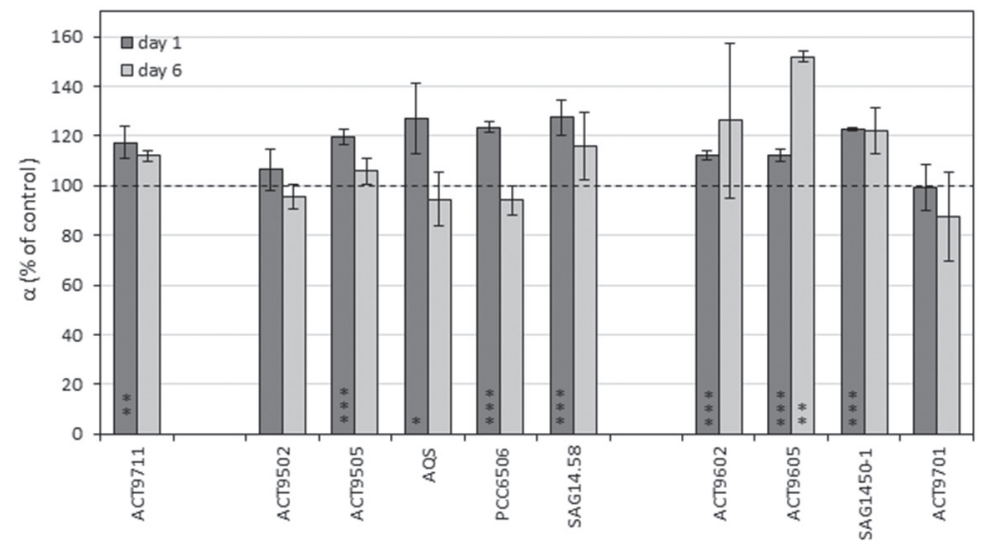

Fig. 7. Effect of cell free filtrates on Scenedesmus quadricauda's maximum quantum yield for whole chain electron transport $(\alpha)$ of photosystem II. Left group of bars are $S$. quadricauda, central group of bars are potentially toxic cyanobacteria and right group of bars are non-toxic cyanobacteria. $\alpha$ was calculated as $\%$ of that of control (average $\pm \mathrm{SD}$ ). $t$-test results between the control and the treatment are shown as: $* \mathrm{P}<0.05, * * \mathrm{P}<0.01, * * * \mathrm{P}<0.001$

Table 2

Results of the two-way ANOVA

\begin{tabular}{|l|c|c|c|c|c|c|}
\hline \multirow{2}{*}{} & \multicolumn{2}{|c|}{ Strain } & \multicolumn{2}{c|}{ Time } & \multicolumn{2}{c|}{ Interaction } \\
\cline { 2 - 7 } & $\mathrm{F}$ & $\mathrm{P}$ & $\mathrm{F}$ & $\mathrm{P}$ & $\mathrm{F}$ & $\mathrm{P}$ \\
\hline $\mathrm{I}_{\mathrm{k}}$ & 10.32 & $<0.001$ & 15.21 & $<0.001$ & 4.187 & 0.002 \\
\hline $\mathrm{ETR}_{\max }$ & 8.67 & $<0.001$ & 126.9 & $<0.001$ & 1.524 & 0.187 \\
\hline$\alpha$ & 5.794 & $<0.001$ & 725 & $<0.001$ & 3.788 & 0.003 \\
\hline $\mathrm{F}_{\mathrm{v}} / \mathrm{F}_{\mathrm{m}}$ & 22.87 & $<0.001$ & 81.6 & $<0.001$ & 2.693 & 0.021 \\
\hline $\mathrm{qP}$ & 17.82 & $<0.001$ & 15.49 & $<0.001$ & 3.418 & 0.006 \\
\hline $\mathrm{qN}$ & 84.43 & $<0.001$ & 759.5 & $<0.001$ & 7.922 & $<0.001$ \\
\hline
\end{tabular}


non-toxic strains, respectively ( $\mathrm{P}<0.001$ ) (Fig. 7). After 6 days of exposure, no difference was observed, although $\alpha$ was still 2-20\% higher (Fig. 7). Acute exposure to strains ACT9711 (self-exposure), ACT9505, AQS, PCC6506, SAG14.58, ACT9602, ACT9605 and SAG1450-1 increased $\alpha$ of the S. quadricauda culture, but after 6 days only ACT9605 had a significant effect $(\mathrm{P}=0.003)$.

Further analysis of our data showed that both the CFFs and incubation time influenced the variability of the photochemical parameters in S. quadricauda (Table 2). Time as a factor was more influential, sometimes altering the direction of the effect, i.e. the effect of the acute exposure was occasionally reversed by day 6 .

\section{DISCUSSION}

Within the aquatic ecosystem, algae are usually highly abundant and diverse components, constituting a large community rich in systematic and ecologically significant interactions. Studies on the dynamics of these interactions are scarce, thus, this lack of information can hinder the understanding of succession in algal communities.

Succession, i.e. the process of species replacement with time occurs as a result of performance differences among the constituents of a given community. The course of succession in algal communities depends on a complex set of interactions between allogenic and autogenic, as well as biotic and abiotic factors of the habitat. While the availability of resources (mostly light and nutrients) is the most widely studied and described driver of succession [29, 44], interspecific allelopathic effects might also directly or indirectly affect the balance of performance within the community $[14,16$, $18,42]$.

Contrary to marine systems, most of the observations on freshwater phytoplankton allelopathy focus on cyanobacteria [8]. Until recently, a number of bioactive cyanobacterial metabolites have been discovered by screening programs [43], on the other hand, their natural function is generally unknown, presumably related to the regulation and succession of algal and bacterial populations [7, 14-16].

Our results show that the CFFs of cyanobacteria do exert influence on the performance of the green alga $S$. quadricauda through affecting its photochemical characteristics. Some CFF treatments had no effect, while others had a positive effect on $S$. quadricauda, however, the most significant impacts were typically negative. Among the cyanobacterial species tested, all strains of $\mathrm{N}_{2}$-fixing C. raciborskii (ACT9205, ACT9505 and AQS) significantly decreased the $\mathrm{ETR}_{\max }$ of $S$. quadricauda. The inhibitory effect of the exudates of C. raciborskii strains varied between $10 \%$ and $42 \%$. Figueredo et al. [7] also described this phenomenon in four non-toxic C. raciborskii strains isolated from Lagoa Santa (Brazil) that disturbed the PSII activity of several phytoplankton species (chlorophytes, cyanobacteria and diatoms). On the other hand, Leão et al. [17] tested five C. raciborskii strains (including CYN producing AQS) and observed no or very small effect on the green alga Ankistrodesmus falcatus with the exception of a non-toxic strain. The results of this study also show that the effect is highly strain dependent, suggesting that strain composition in the 
algal community could be a very important influencing factor during succession. Data presented in our study show that besides the picocyanobacterium strain, the performance of $S$. quadricauda was also significantly inhibited by $\mathrm{N}_{2}$-fixing genera (Cylindrospermopsis and Aphanizomenon). Other studies [7, 38] also implied that filamentous cyanobacteria of the Fischerella, Nostoc, Anabaena, Scytonema, and Calothrix genera, all of which are nitrogen-fixing, heterocytic organisms, can produce metabolites with algicidal effects. The bioactive chemicals excreted by algal cells can be inhibitors and enhancers as well, depending on the environment and target species $[18,41]$. Keating $[14,15]$ demonstrated that the filtrates of various cyanobacterial species generally inhibited their immediate predecessors and stimulated their immediate successors in the natural phytoplankton bloom sequence.

It was noted that inhibition is more effective when both species come from the same lake [15], although others suggested that allelopathy may promote invasiveness [7]. Our result show that the exudates of the C. raciborskii strains isolated from Lake Balaton (ACT9205 and ACT9505) displayed stronger inhibition on the green alga isolated from same lake than AQS, which originated from Australia.

The underlying mechanism of these allelopathic effects in not yet known. The present work, in agreement with the results of Leão et al. [17], indicates that neither the cyanotoxin (MYC, CYN and ATX) producing, nor the non-toxic strains showed any systematic effect on the performance of $S$. quadricauda. Although we did not make a toxin producing test for MYC, CYN and ATX, growth conditions of the tested strains (BG-11 medium, $22{ }^{\circ} \mathrm{C}, 80 \mu \mathrm{mol} \mathrm{m}^{-2} \mathrm{~s}^{-1}$ irradiance) were the same as those under which cyanotoxin production was detected [4, 21-23, 31]. MYC, CYN and ATX are extremely toxic to vertebrates, however, their ecological role is still largely unknown. Several cases were reported in which cyanotoxins exerted inhibitory effects on photoautotrophs $[13,34]$, though their role remains uncertain and their bioactivity has not been associated with an ecological function on the phytoplankton level [16].

This study also showed that with time the effect of the acute exposure was occasionally reversed. This reversal might be attributed to the slow degradation of these biomolecules, suggesting that the impact of the allelopathic molecules could only be effective on a short timescale or distance. In benthic and periphytic habitats, algae are in contact and allelochemicals may be easily translocated from the emitter to target species [8]. On the other hand, stochastic contact between emitted molecules and target organisms in the pelagic zone may take a longer time due to larger distances and variable mixing conditions.

Among all the treatments, exposure to CFF of the picoplanktonic cyanobacterium (Cyanobium gracile ACT9701) had the most remarkable effect on the photosynthetic performance of $S$. quadricauda. Picoplanktonic cyanobacteria (cell size 0.2 to 2.0 $\mu m$ ), despite their ubiquity, are a group of organisms still relatively poorly known. Autotrophic picoplankton can constitute up to $90 \%$ of total phytoplankton biomass in the oceans and up to $43 \%$ in freshwaters $[11,19,40]$. The warming of aquatic ecosystems has been found to favour the growth of these pico-sized organisms [10, 28], however, knowledge with regard to their toxicity is still scarce. A few reports about 
the secretion of microcystins, neurotoxins or lipopolysaccharides by picocyanobacteria $[1,10]$ and chemically undetermined allelocemicals in Synechococcus $[15,35-37]$ have been published.

In conclusion, by using a PAM fluorometric method, we were able to show the effect of cyanobacterial CFFs on the performance of $S$. quadricauda and for the first time also that the freshwater picocyanobacterium Cyanobium gracile has strong negative effect on the coexisting green alga. Neither the cyanotoxin (MYC, CYN and ATX) producing, nor the non-toxic strains showed any systematic effect on the photosynthetic performance of $S$. quadricauda. The various strains of $C$. raciborskii also inhibited the performance of the green alga, independently of their origin. There is still insufficient information on the occurrence and consequences of the allelopathic effects of cyanobacteria in marine, brackish and freshwater ecosystems. Thus, a better understanding of the factors affecting the release of allelopathic compounds and of the mechanisms of their effects requires further research.

\section{ACKNOWLEDGEMENTS}

The research was supported by the Bolyai Research Fund. We are grateful to Martin L. Saker (Interdisciplinary Centre of Marine and Environmental Research, CIIMAR, University of Porto, Portugal) for the C. raciborskii strain of AQS.

\section{REFERENCES}

1. Bláha, L., Maršálek, B. (1999) Microcystin production and toxicity of picocyanobacteria as a risk factor for drinking water treatment plants. Algol. Stud. 92, 95-108.

2. Bilger, W., Schreiber, U. (1986) Energy dependent quenching of dark-level chlorophyll fluorescence in intact leaves. Photosynth Res. 10(3), 303-308.

3. Ciscar, J. C., Feyen, L., Soria, A. (2014) Climate impacts in Europe. The JRC PESETA II project. JRC scientific and politicy reports, EUR 26586EN.

4. Dyble, J., Tester, P. A., Litaker, R. W. (2006) Effects of light intensity on cylindrospermopsin production in the cyanobacterial HAB species Cylindrospermopsis raciborskii. Afr. J. Mar. Sci. 28, 309-312.

5. Eilers, P. H. C., Peeters, J. C. H. (1988) A model for the relationship between light intensity and the rate of photosynthesis in phytoplankton. Ecol. Model 42, 199-215.

6. Falkowski, P. G. (1992) Molecular ecology of phytoplankton photosynthesis. In: Falkowski, P. G., Woodhead, A. D. (eds) Primary Productivity and Biogeochemical Cycles in the Sea. Plenum Press, New York, pp. 47-67.

7. Figueredo, C. C., Giani, A., Bird, D. F. (2007) Does allelopathy contribute to Cylindro-spermopsis raciborskii (Cyanobacteria) bloom occurrence and geographic expansion? J. Phycol. 43, 256-265.

8. Gross, E. M. (2003) Allelopathy of aquatic autotrophs. Crit. Rev. Plant Sci. 22, 313-339.

9. Iwamura, T., Nagai, H., Ichimura, S. (1970) Improved methods for determining contents of chlorophyll, protein, ribonucleic acid, deoxyribonucleic acid in planktonic populations. Int. Rev. ges. Hydrobiol. 55, 131-147.

10. Jakubowska, N., Szeląg-Wasielewska, E. (2015) Toxic picoplanktonic cyanobacteria-Review. Mar Drugs 13, 1497-1518.

11. Jasser, I., Lehtovaara, A., Arvola, L. (2006) Seasonality and coexistence of autotrophic pico- and nanoplankton and zooplankton in three boreal lakes. Verhandlungen des Internationalen Verein Limnologie 29, 1413-1416. 
12. Jöhnk, K. D., Huisman, J., Sharples, J., Sommeijer, B., Visser, P. M., Stroom, J. M. (2008) Summer heatwaves promote blooms of harmful cyanobacteria. Glob. Change Biol. 14, 495-512.

13. Kearns, K. D., Hunter, M. D. (2001) Toxin-producing Anabaena flos-aquae induces settling of Chlamydomonas reinhardtii, a competing motile alga. Microb. Ecol. 42, 80-86.

14. Keating, K. I. (1977) Allelopathic influence on blue-green bloom sequence in a eutrophic lake. Science 196, 885-887.

15. Keating, K. I. (1978) Blue-green algal inhibition of diatom growth: transition from mesotrophic to eutrophic community structure. Science 199, 971-973.

16. Leăo, P. N., Vasconcelos, M. T. S. D., Vasconcelos, V. M. (2009) Allelopathy in freshwater cyanobacteria. Crit. Rev. Microbiol. 35, 271-282.

17. Leăo, P. N., Vasconcelos, T. M. S. D., Vasconcelos, V. M. (2009) Allelopathic activity of cyanobacteria on green microalgae at low cell densities. Eur. J. Phycol. 44, 347-355.

18. Legrand, C., Rengefors, K., Fistarol, G. O., Granéli, E. (2003) Allelopathy in phytoplankton biochemical, ecological, and evolutionary aspects. Phycologia 42, 406-419.

19. Li, W. K. W., Suba Rao, D. V., Harrison, W. G., Smith, J. C., Cullen, B., Irwin, B., Platt, T. (1983) Autotrophic picoplankton in the tropical ocean. Science 219, 292-295.

20. Maxwell, K., Johnson, G. N. (2000) Chlorophyll fluorescence-a practical guide. J. Exp. Botany 51 , 659-668.

21. Mazmouz, R., Chapuis-Hugon, F., Mann, S., Pichon, V., Méjean, A., Ploux, O. (2010) Biosynthesis of cylindrospermopsin and 7-epicylindrospermopsin in Oscillatoria sp. strain PCC 6506: Identification of the cyr gene cluster and toxin analysis. App. Environ. Microb. 76, 4943-4949.

22. Meriluoto, J., Spoof, L., Codd, G. A. (2017) Handbook of Cyanobacterial Monitoring and Cyanotoxin Analysis. John Wiley \& Sons Ltd., United Kingdom.

23. Oberholster, P. J., Myburgh, J. G., Govender, D., Bengis, R., Botha, A.-M. (2009) Identification of toxigenic Microcystis strains after incidents of wild animal mortalities in the Kruger National Park, South Africa. Ecotox. Environ. Safety 72, 1177-1182

24. O’Neil, J. M., Davis, T. W., Burford, M. A., Gobler, C. J. (2012) The rise of harmful cyanobacteria blooms: The potential roles of eutrophication and climate change. Harmful Algae 14, 313-334.

25. Padisák, J., Reynolds, C. S. (1998) Selection of phytoplankton associations in Lake Balaton, Hungary, in response to eutrophication and restoration measures, with special reference to the cyanoprokaryotes. Hydrobiologia 384, 41-53.

26. Paerl, H. W., Paul, V. J. (2012) Climate change: links to global expansion of harmful cyanobacteria. Water Res. 46, 1349-1363.

27. Pick, F. R. (2016) Blooming algae: A Canadian perspective on the rise of toxic cyanobacteria. Can J. Fish. Aquat. Sci. 73, 1149-1158.

28. Rasconi, S., Gall, A., Winter, K., Kainz, M. J. (2015) Increasing water temperature triggers dominance of small freshwater plankton. PLOS ONE | DOI:10.1371/journal.pone.0140449.

29. Reynolds, C. S. (2006) The Ecology of Phytoplankton. Cambridge University Press, New York.

30. Rippka, R., Deruelles, J., Waterbury, J. B., Herdman, M., Stainer, R. Y. (1979) The cyanobacteria. J. Gen. Microbiol. 111, 1-61.

31. Saker, M. L., Neilan, B. A. (2001) Varied diazotrophies, morphologies, and toxicities of genetically similar isolates of Cylindrospermopsis raciborskii (Nostocales, Cyanophyceae) from Northern Australia. App. Environ. Microb. 67, 1839-1845.

32. Schreiber, U. (1998) Chlorophyll fluorescence: new instruments for special applications. In: Garab, Gy. (ed.) Proceedings of the XIth International Congress on Photosynthesis, Vol. V. Kluwer, Dordrecht, pp. 4253-4258.

33. Schreiber, U., Hormann, H., Neubauer, C., Klughammer, C. (1995) Assessment of photosystem II photochemical quantum yield by chlorophyll fluorescence quenching analysis. Aust. J. Plant Physiol. 22, 209-220.

34. Sedmak, B., Eleršek, T. (2005) Microcystins induce morphological and physiological changes in selected representative phytoplankton. Microb. Ecol. 50, 298-305. 
35. Śliwińska-Wilczewska, S., Pniewski, F., Latała, A. (2016) Allelopathic activity of the picocyanobacterium Synechococcus sp. under varied light, temperature, and salinity conditions. Int. Rev. Hydrobiol. 101, 69-77.

36. Śliwińska-Wilczewska, S., Pniewski, F., Latała, A. (2016) Allelopathic interactions between Synechococcus sp. and Nodularia spumigena under different light conditions. Allelopathy J. 37, 241-252.

37. Śliwińska-Wilczewska, S., Maculewicz, J., Barreiro, A. F., Vasconcebos, V., Latała, A. (2017) Allelopathic activity of picocyanobacterium Synechococcus sp. on filamentous cyanobacteria. J. Exp. Mar. Biol. Ecol. 496, 16-21.

38. Smith, G. D., Doan, N. T. (1999) Cyanobacterial metabolites with bioactivity against photosynthesis in cyanobacteria, algae and higher plants. J. Appl. Phycol. 11, 337-344.

39. Sommer, U., Gliwicz, Z. M., Lampert, W., Duncan, A. (1986) The PEG-Model of seasonal succession of planktonic events in fresh waters. Arch. Hydrobiol. 106, 433-471.

40. Stal, L. J., Albertano, P., Bergman, B., Bröckel, K., Gallon, J. R., Hayes, P. K., Sivonen, K., Walsby, A. E. (2003) BASIC: Baltic Sea cyanobacteria. An investigation of the structure and dynamics of water blooms of cyanobacteria in the Baltic Sea - responses to a changing environment. Continental Shelf Research 23, 1695-1714.

41. Suikkanen, S., Fistarol, G. O., Granéli, E. (2005) Effects of cyanobacterial allelochemicals on a natural plankton community. Mar. Ecol. Prog. Ser. 287, 1-9.

42. Sukenik, A., Eshkol, R., Livne, A., Hadas, O., Rom, M., Tchernov, D., Vardi, A., Kaplan, A. (2002) Inhibition of growth and photosynthesis of the dinoflagellate Peridinium gatunense by Microcystis sp. (cyanobacteria): A novel allelopathic mechanism. Limnol. Oceanogr. 47, 1656-1663.

43. Swain, S. S., Paidesetty, S. K., Padhya, R. N. (2017) Antibacterial, antifungal and antimycobacterial compounds from cyanobacteria. Biomedicine \& Pharmacotherapy 90, 760-776.

44. Tilman, D. (1977) Resource competition between planktonic algae: An experimental and theoretical approach. Ecology 58, 338-348.

45. Vörös, L., Nagy Göde, P. (1993) Long term changes of phytoplankton in Lake Balaton (Hungary). Verh. Int. Verein. Limnol. 25, 682-686. 
